\title{
International Association of Shell and Spatial Structures (IASS) Holger Falter
}

The conference "IASS 2000: "Bridging Large Spans From Antiquity to the Present" took place at the Mimar Sinan University, Istanbul, 29 May - 2 June 2000. It was organized by Dr. Ihsan Mungan. The International Association of Shell and Spatial Structures (IASS) was founded in 1959 by Professor Eduardo Torroja during the International Colloquium on shell structures held in Madrid. The aim of the association was to create a platform for scientists, architects and engineers to exchange their ideas and experience. At this time, shell structures were frequently used throughout the world, although most of them were still being constructed of concrete. Regular meetings have been set up from the beginning and the Bulletin was founded, renamed the Journal in August 1996.

Engineers of note such as Franz Dischinger, Eduardo Torroja, Felix Candela, P.L. Nervi and Anton Tedesko are associated with innumerable concrete shells that were built from the early twenties until the late sixties. The form of all these shells can be described mathematically. It was IASS member Heinz Isler who was the first to experience the possibility of form finding by using wet pieces of textiles hanging between rigid boundaries, loaded only by the dead weight. Reversing this type of form results in the loads being mainly transferred via compression with minimal bending. Very thin double curved shells, such as those built by Isler, are the result. All these developments became a topic in the IASS which became an international institution of high quality. Regular Congresses, Symposia and Colloquia have been held from the early days of IASS on.

In the late sixties space structures of steel, timber and fabrics appeared as a new form of construction. Concrete shells became less frequent. As a consequence, the IASS extended their area of work, now incoorporating all kinds of spatial structures which made it also necessary to rename the Association in IASS. The great disadvantage of concrete shells - i.e. the high costs of scaffolding, the big share of labour work during construction and the inflexible usability of the shells - lead to a stagnation in concrete shell construction in favour of economically erecteable, modular and highly flexible space structures, adding steel tubes by means of nodes. Innumerable systems have been invented and published by the IASS meetings and publications.

Frei Otto's German Pavilion for the EXPO 1968 in Montreal as well as the tension roofs for the Olympics in Munich constituted the starting point for the next generation of spatial structures, the wide range of tension structures using high strength cables for cable nets of air inflated fabric constructions. Frei Otto studied the principle of minimal surfaces in Architecture experimenting with hanging chain nets and soap films, as, for example, described by Michael Emmer in his talk "Architecture and Mathematics: Soap bubbles and soup films" at the 1996 conference, "Nexus: Relationships Between Architecture and Mathematics".

A great variety of geometries are possible and have been built by designers such as Frei Otto, M. Kawaguchi, J. Schlaich or M. Saito. The proceedings of the IASS do well to document these developments. Perhaps due to the wide range of research fields within the 
IASS or the large variety of building materials ranging from concrete, steel, tension cables and glass to membrane fabric, the Conceptual Design of Structures also became a matter of interest in the IASS. This resulted in a Symposium held 1996 in Stuttgart with the main theme "Conceptual Design of Structures".

The Structural Morpology Group of IASS (Working Group No.15) may be of the greatest interest for people who follow the Nexus conferences and the Nexus Network Journal. This group concentrates on the morphology - or science of form - of structures. It is one of the most active working groups, aiming to bridge the gap between the fields of civil engineering and architecture, perhaps leading to a better understanding between the two disciplines. It has about 60 regular members and issues a yearly Newsletter to all members and others interested. Structural Morphology is a new field of engineering, becoming more and more the centre of interest for many different and diverse disciplines. In increasing numbers designers are becoming aware of the fact that knowledge of form is a very important aspect of all human activities, especially in works of creativity. Just recently the group had the third international colloquium, "Structural Morphology - Bridge between Civil Engineering and Architecture", held in Delft from 17-19 August 2000.

During the last 10 years, historic structures have become a topic in the IASS as well. This development started with the first IASS Conference, held in Istanbul in 1988. Another conference followed in 1993 and finally the third symposium in Istanbul, held from 29 May to 2 June 2000, organised by I.Mungan from Mimar Sinan University, the theme of which was "Bridging Large Spans From Antiquity to the Present".

Again a wide range of topics have been presented at this year's symposium on reinforced concrete shells and steel structures, as well as tension and membrane foldable structures. There was also a big emphasis on seismic protection and historic structures. Just recently, another group (Working Group No. 17) was established to concentrate on historic structures. Contributions on historic structures tried to view these in their entirety, using an interdisciplinary approach.

Now in its 41 st year, the IASS proved once again to be a suitable platform for many disciplines, not only for engineers and architects. The 2001 meeting will be held in Japan. For further information about the activities of the International Association for Shell and Spatial Structures and the Working Groups, contact the Secretariat in Madrid:

CEDEX: Laboratorio Central de Estrucutral y Materiales

Alfonso XII, 3

28014 Madrid SPAIN

Tel.: 34-1-335 7409

Fax: 34-1-335-7422

E-mail: Iass@cedex.es

First published in the NNJ online October 2000 


\section{The reporter}

Holger Falter studied structural engineering at the University of Stuttgart. After getting his first degree in 1991 he continued his studies at the Institute of Structural Design II at the University of Stuttgart and the Politecnico di Milan in Italy. In 1998 he received his Ph.D. in Engineering at the University of Stuttgart. He published several articles on the "Conceptual Design of Structures". At the Nexus conference in 1998 he presented a paper entitled "The Influence of Mathematics on the Development of Structural Form". He currently works for Ove Arup Germany in London. 